\title{
Performance Investigation of Automobile Radiator Operated with ZnFe2O4 Nano Fluid based Coolant
}

\author{
Ajay Tripathi ${ }^{1, a^{*}}$, H. Chandra ${ }^{2, b}$ \\ $2{ }^{1}$ Automobile Engineering Department, RJIT, BSF Academy Tekanpur (Gwalior, MP), India \\ ${ }^{2}$ V.E.C Lakhanpur Sarguja University Ambikapur (Chattisgarh), India
}

\begin{abstract}
The cooling system of an Automobile plays an important role in its performance, consists of two main parts, known as radiator and fan. Improving thermal efficiency of engine leads to increase the engine's performance, decline the fuel consumption and decrease the pollution emissions. Water and ethylene glycol as conventional coolants have been widely used in radiators of an automotive industry for many years. These heat transfer fluids offer low thermal conductivity. With the advancement of nanotechnology, the new generation of heat transfer fluids called, "nanofluids" have been developed and researchers found that these fluids offer higher thermal conductivity compared to that of conventional coolants. This study focused on the preparation of Zinc based nanofluids $\left(\mathrm{ZnFe}_{2} \mathrm{O}_{4}\right)$ using chemical co-precipitation method and its application in an automotive cooling system along with mixture of ethylene glycol and water (50:50). Relevant input data, nanofluids properties and empirical correlations were obtained from literatures to investigate the heat transfer enhancement of an automotive car radiator operated with nano fluid-based coolants. It was observed that, overall heat transfer coefficient and heat transfer rate in engine cooling system increased with the usage of nanofluids (with ethylene glycol the base-fluid) compared to ethylene glycol (i.e. basefluid) alone. It is observed that, about $78 \%$ of heat transfer enhancement could be achieved with the addition of $1 \%$ $\mathrm{ZnFe}_{2} \mathrm{O}_{4}$ particles in a base fluid at the Reynolds number of $84.4 \times 10^{3}$ and $39.5 \times 10^{3}$ for air and coolant respectively
\end{abstract}

\section{Introduction}

Continuous technological development in automotive industries has increased the demand for high efficiency engines. A high efficiency engine is not only based on its performance but also for better fuel economy and less emission. There are many systems which influence the engine performance like fuel ignition system, emission system, cooling system, etc. one of the parameters which affects the performance of engine is the cooling rate of radiator in engine cooling system. Addition of fins is one of the approaches to increase the heat transfer rate of the radiator. It provides greater heat transfer area and enhances the air convective heat transfer coefficient. However, traditional approach of increasing the cooling rate by using fins has already reached to their limit [1]. As a result, there is a need of new and innovative heat transfer fluids for improving heat transfer rate in an automotive car radiator. In addition, heat transfer fluids at air and fluid side such as water and ethylene glycol exhibit very low thermal conductivity. With the advancement of nanotechnology, the new generation of heat transfer fluids called, "Nanofluids" have been developed and researchers found that these fluids offer higher thermal conductivity compared to that of conventional coolants. Nanofluids seem to be potential replacement of conventional coolants in engine cooling system. Recently there have been researches finding which highlights superior heat transfer performances of Nanofluids. It can be applied in many devices for better performances (i.e. energy, heat transfer and other performances). Nanofluids are formed by suspending metallic or non-metallic oxide nano-particles in traditional heat transfer fluids. This newly introduced category of cooling fluids containing ultrafine nanoparticles $(1-100 \mathrm{~nm})$ has displayed interesting behavior during experiments including increased thermal conductivity and improved heat transfer coefficient compared to a pure fluid. The use of nano-fluid as coolants will leads to smaller size and better positioning of the radiators. It also increases the efficiency of the system with less amount of fluid.

It results that coolant pumps could be shrunk and engines could be operated at higher temperatures. These novel and advanced concepts of coolants offer exciting heat transfer characteristics compared to conventional coolants. Yu et al., [2] reported that about $15-40 \%$ of heat transfer enhancement can be achieved by using various types of Nanofluids. This translates into a better aerodynamic feature for design of an automotive car frontal area. Coefficient of drag can be minimized and fuel efficiency can be improved. Choi [3] reported a project to target fuel savings for the automotive industries through the development of energy efficient nanofluids

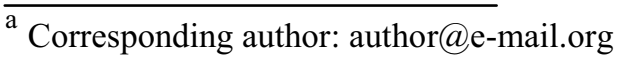


and smaller and lighter radiators. A major goal of the nano-fluid project was to reduce the size and weight of the vehicle cooling systems by greater than $10 \%$ regardless of the cooling demands of higher power engines. Nanofluids enable the potential to allow higher temperature coolants and higher heat rejection in the automotive engines. A higher temperature radiator could reduce the radiator size approximately $30 \%$. This translates into reduced aerodynamic drag, fluid pumping and fan requirements, leading to possibly a $10 \%$ fuel savings. In addition, heat transfer fluids at air and fluid side such as water, ethylene glycol and mixture of ethylene glycol + water (50:50) combination exhibit very low thermal conductivity. As a result there is a need for new and innovative heat transfer fluids for improving heat transfer rate in an automobile radiator. Nanofluids seem to be potential replacement of conventional coolants in engine cooling system. Recently there have been considerable research findings highlighting superior heat transfer performances of nanofluids. Yu et al., [2] reported that about $15-40 \%$ of heat transfer enhancement can be achieved by using various types of nanofluids. With these superior characteristics, the size and weight of an automotive car radiator can be reduced without affecting its heat transfer performance. This translates into a better aerodynamic feature for design of an automotive car frontal area. Coefficient of drag can be minimized and fuel consumption efficiency can be improved.

Therefore, this study attempts to investigate the heat transfer characteristics of an automobile radiator using mixture of ethylene glycol + water (50:50) combination based $\mathrm{ZnFe}_{2} \mathrm{O}_{4}$ nanofluids as coolants. Thermal performance of an automobile radiator operated with nanofluids is compared with a radiator using conventional coolants. The effect of volume fraction of the $\mathrm{ZnFe} 2 \mathrm{O} 4$ nano-particles with base fluids on the thermal performance and potential size reduction of a radiator were also carried out. $\mathrm{ZnFe}_{2} \mathrm{O}_{4}$ nano-particles were chosen in this study.

\section{Literature Review on Radiator of heat transfer using coolant and Nano-fluid}

The automotive industry is continuously involved in strong competitive aspects (performance, fuel consumption, aesthetics, safety, etc.). The air-cooled heat exchangers found in a vehicle (radiator, AC condenser and evaporator, charge air cooler, etc.) has an important role in its weight and also in the design of its front-end module, which also has a strong impact on the car aerodynamic behavior. Looking at these challenges, an optimization process is mandatory to obtain the best design compromise between performance, size/shape and weight. In looking for ways to improve the aerodynamic designs of vehicles, and subsequently the fuel economy, manufacturers must reduce the amount of energy needed to overcome wind resistance on the road. At high speeds, approximately $65 \%$ of the total energy output from a truck is expended in overcoming the aerodynamic drag. This fact is partly due to the large radiator in front of the engine positioned to maximize the cooling effect of oncoming air. The use of nanofluids as coolants would allow for smaller size and better positioning of the radiators. Leong et al. [4] attempted to investigate the heat transfer characteristics of an automotive car radiator using ethylene glycol based copper nano-fluid numerically. Thermal performance of an automotive car radiator operated with nano-fluid has been compared with a radiator using conventional coolants. Vajjha et al. [5] have been numerically studied a three-dimensional laminar fow and heat transfer with two different nanofluid, $\mathrm{Al}_{2} \mathrm{O}_{3}$ and $\mathrm{CuO}$, in the ethylene glycol/water mixture circulating through the fat tubes of an automobile radiator to evaluate their superiority over the base fluid. Convective heat transfer coefficient along the fat tubes with the nanofluid fow showed considerable improvement over the base fluid.

Eastman et al. [6] observed that the thermal conductivity of ethylene glycol nanofluids containing $0.3 \%$ volume fraction of copper particles can be enhanced up to $40 \%$ compared to that of ethylene glycol base-fluid. Hwang et al. [5] established that thermal conductivity of the nanofluids depends on the volume fraction of particles and thermal conductivity of basefluid and particles. Peyghambarzadeh et al. [7] have recently investigated the application of $\mathrm{Al} \mathrm{O}$ /water nanofluids in the car radiator by calculating the tube side heat transfer coefficient. They have recorded the interesting enhancement of $45 \%$ comparing with the pure water application under highly turbulent condition. In the other study, Peyghambarzadeh et al. [8] have used different base fluids including pure water, pure ethylene glycol, and their binary mixtures with $\mathrm{Al}_{2} \mathrm{O}_{3}$ nanoparticles and once again it was proved that nanofluids improves the cooling performance of the car radiator extensively.

Lee et al. [9] calculated the thermal conductivity of low volume concentration of aqueous alumina $\left(\mathrm{Al}_{2} \mathrm{O}_{3}\right)$ nanofluids produced by two-step method. Authors inferred that the thermal conductivity of aqueous nanofluids increases linearly with the addition of alumina particles. Thermal conductivity of zinc dioxide ethylene glycol $\left(\mathrm{ZnFe}_{2} \mathrm{O}_{4}+\mathrm{EG}\right)$ based nanofluids was investigated by $\mathrm{Yu}$ et al. [2]. They obtained about $26.5 \%$ enhancement of thermal conductivity by adding $5 \%$ volume fraction of zinc dioxide nanoparticles in ethylene glycol. Present study concluded that size of nanoparticles and viscosity of the nanofluids played a vital role in thermal conductivity enhancement ratio of them.

Naraki et al. [10] found that thermal conductivity of $\mathrm{CuO} /$ water nanofluids much higher than that of base fluid water. He found that the overall heat transfer coefficient increases with the enhancement in the nanofluid concentration from 0 to $0.4 \mathrm{vol}$. \%. Conversely, the implementation of nanofluid increases the overall heat transfer coefficient up to $8 \%$ at nanofluid concentration of 0.4 vol. $\%$ in comparison with the base fluid.

Argonne researchers, Singh et al. [11], have determined that the use of high-thermal conductive nanofluid in radiators can lead to a reduction in the frontal area of the radiator by up to $10 \%$. This reduction in aerodynamic drag can lead to a fuel savings of up to 
$5 \%$. The application of nano-fluid also contributed to a reduction of friction and wear, reducing parasitic losses, operation of components such as pumps and compressors, and subsequently leading to more than $6 \%$ fuel savings.

\section{Experimental test rig and procedure}

\subsection{Experimental test rig}

Fig. 1 shows schematic diagram of experimental set up which consists of closed loop circuit. The experimental test rig includes reservoir and heating element, water pump, Rotameter, DC current based radiator fan and Automobile radiator. Water pump gives the flows 15-17 [LPM]; the flow rate of the test section is regulated by one control valve which is adjustable to the recycle line as shown in fig 1 . The working fluid fills $40 \%$ of the storage tank whose total volume is 40 [lit]. The total volume of the circulating liquid is constant in all the experiments. The circuit include $0.30 \mathrm{~m}$ diameter pipeline which is made of the steel pipe. A Rotameter is used to measure the flow through the test section. The specification of the Rotameter is 100-1000 [LPH]. For heating the working fluid an electric heater of capacity 2000 [Watt] and controller were used to maintain the temperature $60-80\left[{ }^{\circ} \mathrm{C}\right]$. Two $\mathrm{K}$ type thermocouples were implemented on the flow line to record the radiator inlet and outlet temperature. Two thermocouples $\mathrm{K}$ types are installed in the radiator to measure the wall temperature of the radiator.

\subsection{Experimental Procedure}

The analysis on radiator specification and condition of the fluids shown in table 1 and 2 . How ever nano particle volume fraction air Reynolds number and mass flow rate of the coolant flowing though radiator were varied in order to determine the thermal performance of the radiator using nanofluids. The procedures of each analysis are explained below.

a) Influence of the volume fraction of $\mathrm{ZnFe}_{2} \mathrm{O}_{4}$ nanoparticles on the thermal performance of an automobile radiator. In the study air Reynolds number and mass flow rate of the coolant were kept fixed at $84.4 \times 10^{3}$ and $0.03[\mathrm{~kg} / \mathrm{s}]$. However the concentration of $\mathrm{ZnFe}_{2} \mathrm{O}_{4}$ nanoparticles was increased from 0 to $1.5 \%$. Total heat transfer, overall heat transfer coefficient and effectiveness of the radiator were determined.

b) Influence of the air Reynolds number on the thermal performance of automobile radiator. Air Reynolds number was varied from $84.4 \times 10^{3}$ to $91.3 \times 10^{3}$ while mass flow rate of the coolant was kept fixed to $0.03[\mathrm{~kg} / \mathrm{s}]$. The analysis also included a comparison of the thermal performance of radiator with nano-fluids at different volume fractions. This part focused on effectiveness .overall heat transfer coefficient based on the air side and total heat transfer of an automobile radiator.

c) Influence of mass flow rate of the coolant on the thermal performance of automobile radiator. Mass
Flow rate of the coolant were varied from 0.03 to $0.09[\mathrm{~kg} / \mathrm{s}]$ while air Reynolds number was kept fixed $84.4 \times 10^{3}$. The analysis also included a comparison of the thermal performance of automobile radiator with nanofluid with nanofluids at different volume concentration. This part of the analysis focused on total heat transfer, overall heat transfer coefficient and effectiveness $o$ an automobile radiator.

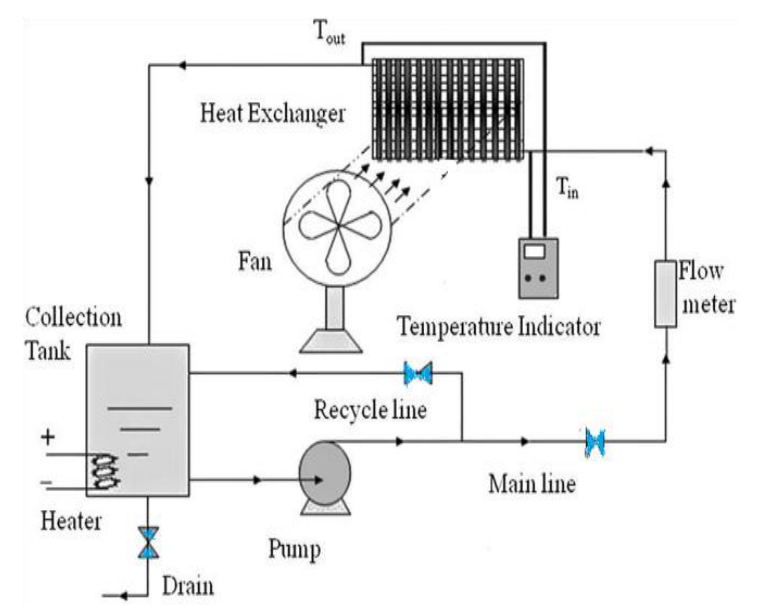

Figure 1. Schematic of experimental set up

\begin{tabular}{|l|l|l|l|}
\hline $\begin{array}{l}\text { Serial } \\
\text { number }\end{array}$ & Description & Air & Coolant \\
\hline $\mathbf{1}$ & $\begin{array}{l}\text { Fluid inlet } \\
\text { temperature }\end{array}$ & $\begin{array}{l}\text { (Assume } \\
\left.\mathrm{T}_{\mathrm{a}}=24\right)\end{array}$ & $\begin{array}{l}85 \\
(\text { Assume Ta= } \\
60)\end{array}$ \\
\hline $\mathbf{2}$ & Core width & $315[\mathrm{~mm}]$ & $315[\mathrm{~mm}]$ \\
\hline $\mathbf{3}$ & Core length & $415[\mathrm{~mm}]$ & $415[\mathrm{~mm}]$ \\
\hline $\mathbf{4}$ & Core depth & $2[\mathrm{~cm}]$ & $2[\mathrm{~cm}]$ \\
\hline $\mathbf{4}$ & Tubes & $\begin{array}{l}8[\mathrm{~mm}](\phi) \times \\
30[\mathrm{~cm}]\end{array}$ & \\
\hline $\mathbf{5}$ & No of tubes & 57 & 57 \\
\hline $\mathbf{6}$ & $\begin{array}{l}\text { Hydraulic } \\
\text { Diameter }\end{array}$ & $7[\mathrm{~cm}]$ & $7[\mathrm{~cm}]$ \\
\hline $\mathbf{7}$ & Fine types & Ruffled & Ruffled \\
\hline $\mathbf{8}$ & $\begin{array}{l}\text { Tubes } \\
\text { arrangement }\end{array}$ & Staggered & Staggered \\
\hline
\end{tabular}

Table 1 - Radiator Specifications

\begin{tabular}{|l|l|c|c|}
\hline Sr no & Properties & $\mathbf{Z n F e}_{2} \mathbf{O}_{\mathbf{4}}$ & $\begin{array}{l}\text { Mixture of } \\
\text { water } \\
\text { +ethylene } \\
\text { glycols }\end{array}$ \\
\hline $\mathbf{1}$ & Density $\left[\mathrm{Kg} / \mathrm{m}^{3}\right]$ & 5012 & 1064 \\
\hline $\mathbf{2}$ & $\begin{array}{l}\text { Specific heat } \\
{[\mathrm{J} / \mathrm{kg} \mathrm{K}]}\end{array}$ & 901.5 & 3370 \\
\hline $\mathbf{3}$ & $\begin{array}{l}\text { Thermal } \\
\text { conductivity } \\
{[\mathrm{W} / \mathrm{mK}]}\end{array}$ & 42.36 & 0.363 \\
\hline $\mathbf{4}$ & $\begin{array}{l}\text { Viscosity } \\
{\left[\mathrm{N} / \mathrm{sm}^{2}\right]}\end{array}$ & - & $10^{-5}$ \\
\hline
\end{tabular}

Table 2: Thermo physical Properties of base Fluid and nanoparticles 


\section{Mathematical formulation of mixture of water +ethylene glycol based CuFe2O4 nanofluids in an automobile radiator}

Mathematical correlation shown in this section is taken from the references [12, $13 \&$ \& 14]. In this paper a comparison is made between the heat transfer performance of radiator by operating with mixture of ethylene glycol, water and nanofluid coolants. It highlighted not only the influence of nanofluids but also volume fraction of $\mathrm{CuFe}_{2} \mathrm{O}_{2}$ nanoparticles to the heat transfer rate of a radiator. Described equations are being incorporated to aid the comparison. The characteristics of nanoparticles and base fluid used in this study are summarized in Table 2. The necessary thermo physical properties in this paper are density, viscosity, specific heat and thermal conductivity. In this paper, density $\left(\rho_{\mathrm{nf}}\right)$ and special heat capacity $\left(\mathrm{C}_{\text {pnf }}\right)$ of $\mathrm{CuFe}_{2} \mathrm{O}_{4} /$ Water nanofluids have been calculated based on empirical correlations proposed by and Xuan [15] as follows:

By assuming that the nanoparticles are well dispersed within the base fluid, i.e. the particle concentration can be considered uniform throughout the system; the effective physical properties of the mixtures studied can be evaluated using some classical formulas [c, d] as usually used for two phase flow. These relations have been used to predict nanofluids physical properties like density, specific heat, dynamic viscosity and thermal conductivity at different temperatures and concentrations.

$$
\begin{gathered}
\rho_{n f}=(1-\varphi) \rho_{f}+\varphi \rho_{f} \\
C_{n f}=\frac{(1-\varphi) C_{f}+\varphi \rho_{p} C_{p}}{\rho_{n f}} \\
\mu_{n f}=\mu_{f} \frac{1}{(1-\varphi)^{2.5}} \\
k_{n f}=\frac{k_{p}+(n-1) k_{b f}-\varphi(n-1)\left(k_{b f}-k_{p}\right)}{k_{p}+(n-1) k_{b f}+\left(k_{b f}-k_{p}\right)} k_{b f}
\end{gathered}
$$

Where, $n$ is empirical shape factor given by $n=3 / \psi$, and $\psi$ is the particle sphericity, defined as the ratio of the surface area of a sphere with volume equal to that of the particle, to the surface. It is obvious that the addition of small amount of nanoparticles can change more or less all the physical properties of the base fluid.

\section{Mathematical formulation for heat transfer in nanofluids}

Thermal performances of a radiator using nanofluids can be calculated using following equations (1)-(24). Calculations were done on air and coolant sides. The rate of heat transferred between nanofluid coolant and airflow in the radiator can be written as follows:

$$
Q=m_{n f} C_{n f}\left(T_{n f o}-T_{n f i}\right)=m_{a} C_{p a}\left(T_{a o}-T_{a i}\right)
$$

Where nf and ai denote the relevant parameters of nanofluid coolant and airflow
The mass flow rates are calculated based on the pump for mixture of water \& ethylene glycol $(50 \%$ volume concentration) +nanofluid and the speed and frontal area for the air as follows:

$$
\begin{aligned}
& m_{n f}=\rho_{n f} V_{n f} A_{\text {tube }} \\
& m_{a}=\rho_{a} v_{a} A_{f r}
\end{aligned}
$$

\subsection{Air Side Calculations}

Initially, air side calculations are performed to determine air heat capacity, air heat transfer coefficient, fin efficiency and total surface temperature effectiveness. These data are needed to calculate heat exchanger effectiveness, NTU number and overall heat transfer coefficient for the nano-fluid side calculation. Air properties are based on temperature at $300 \mathrm{~K}$. The mathematical formulations are shown below.

1. Air Heat Capacity Rate $\mathrm{Ca}$ can be given as Equation (1).

$$
\mathrm{C}_{\mathrm{a}}=\mathrm{m}_{\mathrm{a}} \mathrm{C}_{\mathrm{p}, \mathrm{a}}
$$

Where,

$$
\mathrm{C}_{\mathrm{p}, \mathrm{a}}=1.007 \mathrm{KJ} / \mathrm{KgK} \text { at } 300 \mathrm{~K}
$$

Where, $\quad \sigma_{a}=\frac{A_{o, a}}{A_{f r, a}}$

2. Heat Transfer co-efficient can be expressed as Equation (13)

$$
\begin{aligned}
& \operatorname{Re}_{a}=\frac{G_{a} D_{h, a}}{\mu_{a}} \\
& J_{a}=\frac{0.174}{\operatorname{Re}_{a}}=\frac{h_{a} \operatorname{Pr}_{a}^{2 / 3}}{G_{a} C_{p, a}} \\
& h_{a}=\frac{J_{a} G_{a} C_{p, a}}{\operatorname{Pr}_{a}^{2 / 3}}
\end{aligned}
$$

Where, $\quad \mu_{\mathrm{a}}=0.00001846 \mathrm{Ns} / \mathrm{m} 2$ at $300 \mathrm{~K}$.

\subsection{Nanofluids side calculations}

The parameters needed for nano-fluid side calculation are nano-fluid heat transfer coefficient, nano-fluid heat capacity rate, heat exchanger effectiveness for cross-flow unmixed fluid, heat transfer coefficient based on air side, pressure drop, pumping power and total heat transfer rate.

1. Heat transfer co-efficient can be expressed as Eq. (14)

$$
h_{n f}=\frac{N u_{n f} k_{n f}}{D_{h, n f}}
$$

$\mathrm{K}_{\mathrm{nf}}$ can be obtained by correlation (4)

$$
\begin{array}{r}
N u_{n f}=0.023 \operatorname{Re}_{n f}^{0.8} \operatorname{Pr}_{n f}^{0.3} \\
\operatorname{Re}_{n f}=\frac{G_{n f} D_{h, n f}}{\mu_{n f}}
\end{array}
$$




$$
\begin{aligned}
G_{n, f} & =\frac{m_{n f}}{A_{o, n f}}=\frac{m_{n f}}{\sigma_{n f} A_{f r, n f}} \\
m_{n f} & =\rho_{n f} V_{n f} \\
\operatorname{Pr}_{n f} & =\frac{\mu_{n f} C_{p n f}}{k_{n f}}
\end{aligned}
$$

$\rho_{\mathrm{nf}}, \mathrm{C}_{\mathrm{p}, \mathrm{nf}}$ and $\mu_{\mathrm{nf}}$ are calculated based on correlations (a), (b) and (c) respectively.

2. Heat capacity rate, $\mathrm{C}_{\mathrm{nf}}$ can be expressed as Eq. (20)

$$
\mathrm{C}_{\mathrm{nf}}=\mathrm{m}_{\mathrm{nf}} \mathrm{C}_{\mathrm{pnf}}
$$

3. Overall heat transfer coefficient, based on air side can be expressed as Eq. (21), where wall resistance and fouling factors are neglected.

$$
\begin{gathered}
\frac{1}{U_{a}}=\frac{1}{\eta_{o} h_{a}}+\frac{1}{\left(\frac{\alpha_{n f}}{\alpha_{a}}\right) h_{n f}} \\
\alpha_{n f}=\frac{A_{n f}}{V} \& \alpha_{a}=\frac{A_{a}}{V}
\end{gathered}
$$

4. Total heat transfer rate can be expressed as Eq. (23)

$$
Q=\varepsilon C_{\min }\left(T_{n f, i n}-T_{a, i n}\right)
$$

Where $\mathrm{f}$ is nanoparticle volume concentration and $\rho_{\mathrm{p}}, \rho_{\mathrm{bf}}$ and $\mathrm{C}_{\mathrm{p}, \mathrm{p}}, \mathrm{C}_{\mathrm{bf}}$ are the densities and the specific heats of the nanoparticles and base fluid, respectively.

\section{Results and Discussions:}

\subsection{Influence of volume fraction of $\mathrm{ZnFe2O4}$ particles to thermal performance of an automobile radiator}

In the present paper thermal performance of the Automobile radiator at constant air Reynolds number $\left(84.4 \times 10^{3}\right)$ and constant mass flow rate $0.03[\mathrm{Kg} / \mathrm{s}]$ have been carried out.. With increase in the volume fraction of $\mathrm{ZnFe}_{2} \mathrm{O}_{4}$ particles dynamic viscosity of nanofluid has been increased. This parameter influence mass Flow rate of the nanofluid in automobile radiator. The relationship shown in fig. 2 where overall heat transfer coefficient based on the air side increase in the volume concentration of $\mathrm{ZnFe}_{2} \mathrm{O}_{4}$ particles in the base fluid. An overall heat transfer coefficient $390\left[\mathrm{~W} / \mathrm{m}^{2} \mathrm{k}\right]$ can be achieved for $1.5 \% \quad \mathrm{ZnFe}_{2} \mathrm{O}_{4}$ mixture of $\mathrm{EG} /$ water $(50 \%$ volume concentration) nanofluid compared $215\left[\mathrm{~W} / \mathrm{m}^{2} \mathrm{k}\right]$ for based fluid. It showed that it increased overall heat transfer coefficient based on air side up to $72 \%$ from above figure at constant air Reynolds number $\left(84.4 \times 10^{3}\right)$ and constant mass flow rate $(0.03[\mathrm{~kg} / \mathrm{s}])$ This study also found that heat transfer rate is increased exponentially as the volume fraction of $\mathrm{ZnFe}_{2} \mathrm{O}_{4}$ particles are increased as shown in fig. 3. This improvement is calculated using Eq. (33). It can be deduced that effectiveness of the radiator is increased with the application of nanofluids. However the percentage of effectiveness does not increase substantially, although the improvement of overall heat transfer coefficient is significant.

\subsection{Influence of air Reynolds number on thermal performance of a radiator}

Nanofluids with higher $\mathrm{ZnFe}_{2} \mathrm{O}_{4}$ volume fraction generates higher overall heat transfer coefficient than that of a base-fluid. Same scenario happened for heat transfer rate where it is proportional to air Reynolds number as shown in fig 4 . About $70 \%$ of heat transfer improvement can be achieved with addition of $1 \% \mathrm{ZnFe}_{2} \mathrm{O}_{4}$ particles at $91.3 \times 10^{3}$ and $39.5 \times 10^{3}$ Reynolds number for air and coolant respectively. Based on the overall heat transfer coefficient and heat transfer rate improvement, percentage reduction of air frontal area can be estimated, at these Reynolds numbers. Percentage improvement of heat transfer rate increases with air Reynolds number.

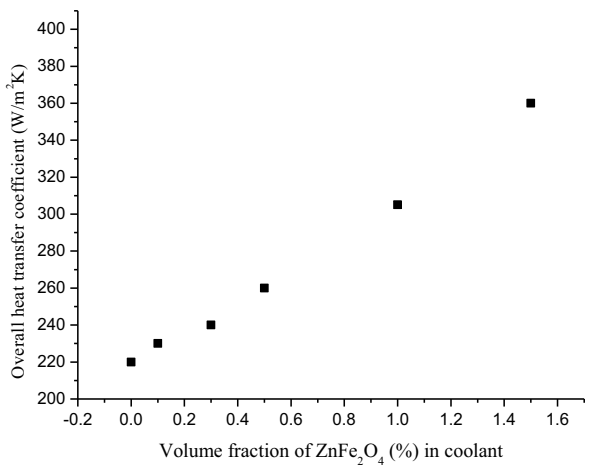

Figure 2. Effect of $\mathrm{ZnFe}_{2} \mathrm{O}_{4}$ particles to the overall heat transfer coefficient based on air side at constant air Reynolds number and constant mass flow rate.

Although results indicated that higher air Reynolds number leads to better heat dissipation process, design of the radiator must ensure the engine operation at optimum temperature. Driving conditions or its speed and engine load must be considered. For instance, car's engine needs to operate at higher load when driving up hill and at the same time air Reynolds number is low due to lower air velocity. Hence, there is possibility for engine to get overheated at this condition. However when driving downhill, an engine only requires operating at lower load and at the same time high air Reynolds number is observed. Eventually engine might be overcooled. Therefore, these aspects must take into consideration when designing automobile radiator.

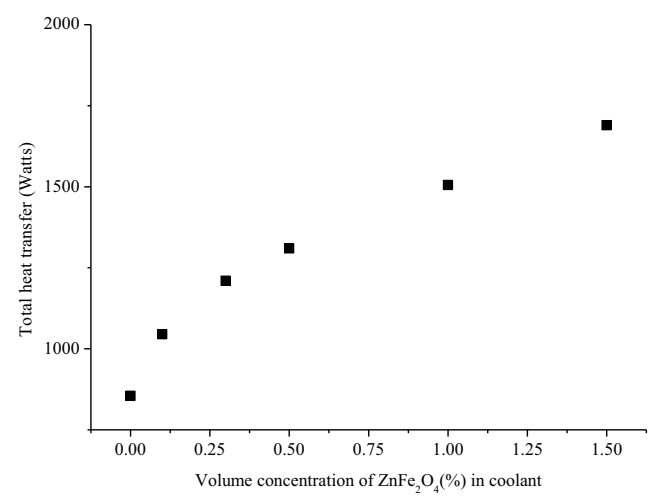

Figure 3. Effect of $\mathrm{ZnFe}_{2} \mathrm{O}_{4}$ particles to total heat transfer at constant air Reynolds number and constant mass flow rate. 


\subsection{Influence of mass flow rate the base fluid on thermal performance of the automobile radiator}

This section presents the effect of coolant Reynolds number on the thermal performance of a radiator at a fixed air Reynolds number $\left(84.4 \times 10^{3}\right)$. Coolant mass flow rate plays vital role in determining the radiator's thermal performance. Engine might be overcooled or overheated if coolant mass flow rate is not properly controlled. The main function of a radiator is to ensure that engine is operating at optimum temperature by not only controlling the air Reynolds number but also mass flow rate. With increase in the mass flow rate of the coolant flowing through automobile radiator, it increases coolant Reynolds number .Overall heat transfer coefficient based on air side is increased with mass flow rate of the coolant flowing through radiator as shown in Fig. 6. The magnitude of this property for nanofluids is higher than that of a base-fluid. Therefore, heat transfer area reduction for the same value of overall heat transfer coefficient can be achieved by using nanofluids. Heat transfer enhancement was also observed with mass flow rate of the coolant.

For instance, with the addition of $1 \% \mathrm{ZnFe}_{2} \mathrm{O}_{4}$ particles, $78 \%$ improvement of heat transfer rate has been achieved at $84.4 \times 10^{3}$ and $39.5 \times 10^{3}$ Reynolds number for air and coolant respectively. It is also observed that the percentage of improvement is decreased with decrease of coolant Reynolds number. Fig. 7 shows heat transfer rate of a radiator using nanofluid is higher than that of a radiator using mixture of water $+\mathrm{EG}(50 \%$ volume concentration).

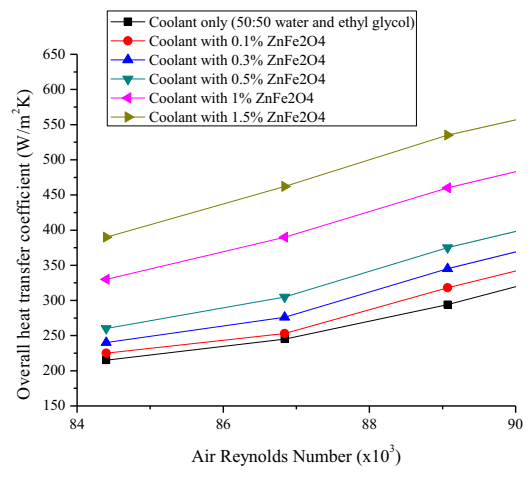

Figure 4. Effect of Air Reynolds number and $\mathrm{ZnFe} 2 \mathrm{O} 4$ volume fraction to Overall Heat Transfer Coefficient Based on Air Side.

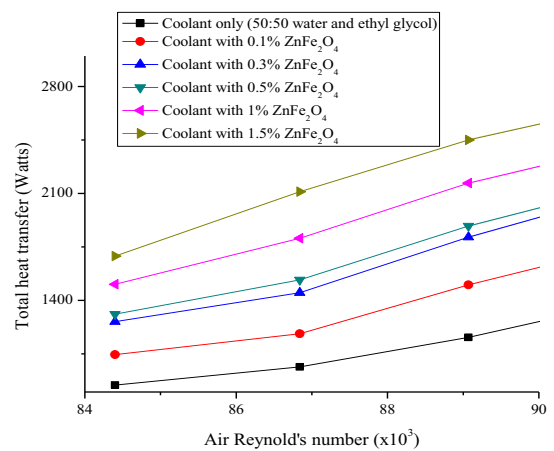

Figure 5. Effect of Air Reynolds number and $\mathrm{ZnFe}_{2} \mathrm{O}_{4}$ volume fraction to total heat transfer.

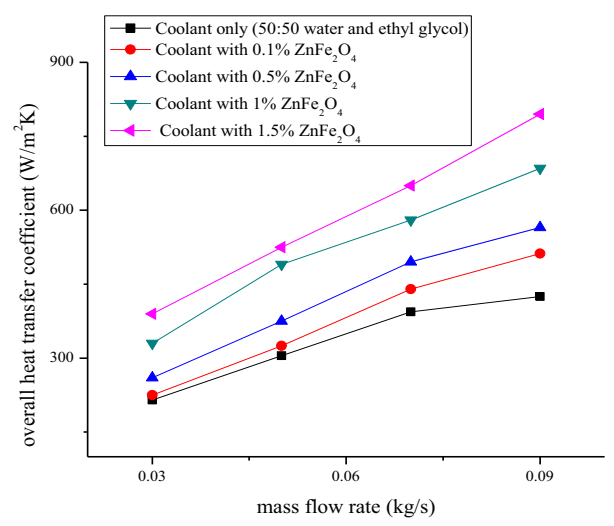

Figure 6. Effect of the mass flow rate to overall heat transfer coefficient based on air side.

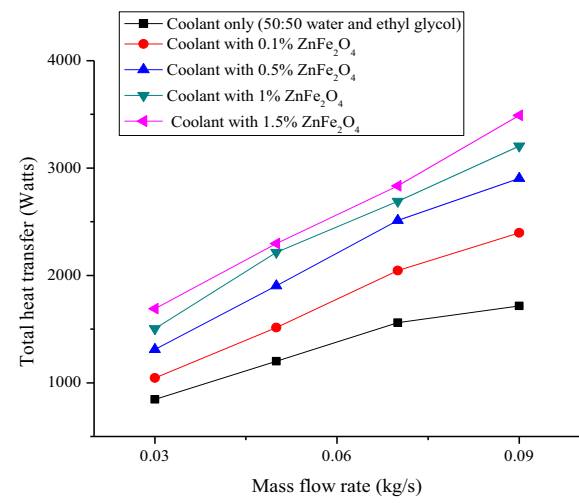

Figure 7. Effect of the mass flow rate to Heat transfer rate of Radiator.

\section{Conclusions}

d) The above work was based on the previous work done by Bhogre et al. [16].

e) Heat transfer rate is increased with increase in volume concentration of nanoparticles (ranging from $0 \%$ to $1.5 \%$ ). About $78 \%$ heat transfer enhancement was achieved with addition of $1 \%$ $\mathrm{ZnFe}_{2} \mathrm{O}_{4}$ particles at $84.4 \times 10^{3}$ air Reynolds number and constant mass flow rate $(0.03[\mathrm{Kg} / \mathrm{s}])$.

f) Thermal performance of a radiator using nanofluid or mixture ethylene glycol water $(50 \%$ Volume concentrations) coolant is increased with air Reynolds Number. About $60 \%$ increment in the total heat transfer and overall heat transfer coefficient based on the air side at constant mass flow rate $(0.09[\mathrm{Kg} / \mathrm{s}])$ and variable air Reynolds number $\left(84.4-91.3 \times 10^{3}\right)$. Overall heat transfer also increases with increase in mass flow rate of mixture.

\section{Acknowledgment}

Authors is acknowledging the support given by Dr. Rashmi Tyagi and Dr. U S Sharma for providing technical support on nanofluid of their project sanctioned by MP Council of Science and Technology, M.P. Vide No 3684/CST/R\&D/Phy Engg. Sc/2012 dated 12.11.2012, 


\section{References}

1) D.P. Kulkarni, R.S. Vajjha, D.K. Das, D. Oliva, Application of aluminum oxide nanofluids in diesel electric generator as jacket water coolant, 'Applied Thermal Engineering' 28 (14-15), (2008), 17741781.

2) W. Yu., D.M. France, S.U.S. Choi, J.L. Routbort, Review and Assessment of Nanofluid Technology for Transportation and Other Applications (No.ANL/ ESD/07-9), 'Energy System Division', Argonne National Laboratory, Argonne, (2007), 109-116.

3) S.U.S. Choi, Nanofluids for improved efficiency in cooling systems, in: Heavy Vehicle Systems Review, 'Argonne National Laboratory', April 1820, (2006).

4) K. Y. Leong, R. Saidur, S.N Kazi, A.H. Mamun, Performance investigation of an automotive car radiator operated with nanofluid-based coolants (nanofluid as a coolant in a radiator), 'Journal of Applied Thermal Engineering', 30, (2010), 26852692.

5) R.S. Vajjha, D.K. Das, P.K. Namburu, Numerical study of fluid dynamic and heat transfer performance of $\mathrm{Al}_{2} \mathrm{O}_{3}$ and $\mathrm{CuO}$ nanofluids in the fat tubes of a radiator, 'International Journal of Heat Fluid Flow', 31/4, (2010), 613- 621.

6) J.A. Eastman, S.U.S. Choi, S. Li, W. Yu, L.J. Thompson, Anomalously increased effective thermal conductivities of ethylene glycol-based nanofluids containing copper nanoparticles, 'Applied Physics Letters' 78 (6), (2001), 718-720.

7) S.M. Peyghambarzadeh, S.H. Hashemabadi, M.S. Jamnani, S.H. Hoseini, Improving the cooling performance of automobile radiator with $\mathrm{Al}_{2} \mathrm{O}_{3}$ /water nanofluid, 'Journal of Applied Thermal Engineering', 31, (2011), 1833-1838

8) S.M. Peyghambarzadeh, S.H. Hashemabadi, M.S. Jamnani, S.H. Hoseini, Experimental study of heat transfer enhancement using water/ethylene glycol based nanofluids as a new coolant for car radiators, 'International Communication in Heat and Mass Transfer', (2011), 1283-1290.

9) J.-H. Lee, K.S. Hwang, S.P. Jang, B.H. Lee, J.H. Kim, S.U.S. Choi, Effective viscosities and thermal conductivities of aqueous nanofluids containing low volume concentrations of $\mathrm{Al}_{2} \mathrm{O}_{3}$ nanoparticles, 'International Journal of Heat and Mass Transfer', (11-12), (2008), 2651-2656.

10) M. Naraki, S.M Peyghambarzadeh, S.H. Hashemabadi, Y. Vermahmoudi, Parametric study of overall heat transfer coefficient of $\mathrm{CuO} /$ water nanofluids in a car radiator, 'International Journal of Thermal Sciences', 66, (2013), 82-90.

11) D. Singh, J. Toutbort, G. Chen, Heavy vehicle systems optimization merit review and peer evaluation, Annual Report, Argonne National Laboratory, (2006).

12) V. Vasu, K.R. Krishna, A.C.S. Kumar, Thermal design analysis of compact heat exchanger using nanofluids, 'International Journal of nonmanufacturing', 2 (3) (2008) 271-287.

13) W.M. Kays, A.L. London, Compact Heat Exchanger, third ed. McGraw-Hill, Inc., United States, (1984).

14) D.G. Charyulu, G. Singh, J.K. Sharma, Performance evaluation of a radiator in a diesel engine e a case study, 'Applied Thermal Engineering', 19, (1999), 625-639.

15) Y. Xuan, W. Roetzel, Conceptions of heat transfer correlation of nanofluids, International 'Journal of Heat and Mass Transfer', 43/19, (2000), 3701-3707.

16) R. A. Bhogare, B.S. Kothavale, M. P. Padmane, S. Pawar, A. Rishi, Performance analysis of automobile radiator operated with Nan fluid based coolant 'International colloquium on Material, Manufacturing and Metrology', ICMMM-2014 Aug 8-9, (2014), IIT Madras, Chennai, India. 